\title{
RETINAL DETACHMENT AT THE POSTERIOR POLE
}

\section{To the Editorial Committee of the British Journal OF OPHTHALMOLOGY}

SIRS,-I read with great interest the recent article by C. I. Phillips (Brit. J. Ophthal., 1958, 42, 749) on retinal detachments at the posterior pole. I agree with his statements, particularly when he says "that most are myopes and some have posterior staphylomata". I should, however, like to stress one point which was not specially mentioned in his article.

Favre (1954) pointed out that, in high myopes with posterior staphyloma, the area near the disc is a likely site for holes which are difficult to see by ordinary methods of ophthalmoscopy. He described two similar cases and specially remarked the importance of slit-lamp examination of the fundus in the diagnosis of such cases.

The so-called "area of Martegiani", at the margins of the posterior staphyloma, is a site that should be specially searched by means of the fundus slit lamp in every case of myopic retinal detachment, even if other holes at the periphery have already been detected (Schiff-Wertheimer, 1957). I have been able to observe this peculiar condition four times, twice in the same eye, in a series of nearly 300 operated cases in the last 3 years. In all my cases the holes were found with the Schepens indirect binocular ophthalmoscope, and not by direct ophthalmoscopy. Slit-lamp examination of the fundus was necessary in each case to confirm the indirect ophthalmoscopic findings, The vitreous was completely detached from the posterior pole in every case and no adhesions were detected between the posterior face of the vitreous and the margins of the retinal hole. I do not propose to discuss here the surgical management of such cases; this will be considered subsequently. In conclusion I repeat that the area near the disc should be carefully examined with the slit lamp before the possible causes of a posterior detachment "without hole" are considered.

Yours faithfully,

ENRIQUE MALBRÁN.

Parera 94,

Buenos AIREs.

February 6, 1959.

\section{REFERENCES}

FAVRE, M. (1954). Ophthalmologica (Basel), 127, 351.

PhILlIPS, C. I. (1958). Brit. J. Ophthal., 42, 749.

SCHIFF-WeRTHEIMER, S. (1957). In "Biomicroscopie du corps vitré et du fond de l'oeil" by A. Busacca, H. Goldmann, and S. Schiff-Wertheimer. Masson, Paris.

\section{BOOK REVIEWS}

Wolff's Diseases of the Eye. Revised by Redmond Smith. 5th edition, 1959. Pp. 226, 150 figs., 8 col. pl. Cassell, London. (42s.)

The fifth edition of Eugene Wolff's handbook on diseases of the eye has been revised by Redmond J. H. Smith. This is a short elementary account of ocular diseases in which the more common conditions are briefly but clearly described for the junior student and general practitioner. The text has been revised and brought up to date, the most 
extensive revision being undertaken of the chapters on glaucoma, uveitis, and the retinopathies. It would be well, however, if more revision were undertaken. In subsequent editions it might be of some advantage to change some of the general arrangements of the original author: for example, the chapter on the methods of perimetry and the visual fields (Chap. xvii) follows far after changes in the fields have been discussed in glaucoma (Chap. vii), and the student is introduced to ophthalmoscopy after he has read about choroiditis. It would be well also to alter the second sentence in the book, for some organisms can be harmful in the conjunctival sac in the absence of injury.

A History of Ophthalmology. By George E. Arrington, Jr. 1959. Pp. 174. MD Publications Inc., New York. (\$4.00.)

This is a short and somewhat slight sketch of the history of ophthalmology from its first known origins in the early civilization of Mesopotamia to recent times, from the mysticism and incantations of the temple to the technological achievements of to-day. But the author does not rest content with the materialistic achievements of the present generation. In his view the development of ophthalmology throughout the centuries and its relationship with the cultures and civilizations in which it flourished indicate that it must turn more and more to a wider interpretation of science in terms of ethics, morality, and humanity. It would seem, however, that this short résumé of factual events in the development of ophthalmology, related with little attempt to clothe them in an integrated philosophy, shows little reason for any such development.

Many will differ from the author in his assessment of the relative value of various contributions to ophthalmological progress. The credit, for example, of pointing out the importance of the avoidance of excessive oxygen in the prevention of retrolental fibroplasia is attributed to Locke. In the table of "Major Contributions" at the end of the volume, only the name of Clifford Walker (not that of Gonin) is associated with the operative treatment of retinal detachment, that of Lundsgaard with fistulizing operations for glaucoma. Few would insert the name of Joseph Pascal as the only contributor to ophthalmic optics since von Helmholtz. There are also more misprints than there ought to be, as well as misspellings, transposed lines, and on p. 150 a transposition of the Code of Hammurabi with the notes on Hippocrates.

Plastische Chirurgie am Auge (Plastic Surgery of the Eyes). By E. WALSER. 1958. Pp. 258, 286 figs. Bergmann, Munich. (D.M. 66.)

This volume by Walser of Munich presents a short and concise account, in the German language, of the more common procedures of plastic surgery associated with the eye and its adnexa. "Plastic Surgery" is interpreted in its widest sense. After a short historical introduction and an assessment of the general indications for plastic procedures, the pre-operative preparation of the patients and their post-operative care, operations on the lids, lacrimal apparatus (including nasal-drainage operations), and conjunctiva are described; chapters successively follow on corneal grafting, the implantation of plastic lenticuli (Ridley, Strampelli, etc.) associated with cataract extraction, the insertion of implants after excision of the globe, remedial procedures for contracted sockets, and the various operations for plastic reconstruction of the orbit particularly after injury. The text is clear and concise, the illustrations are good, the bibliography (40 pages) valuable and the index useful. The book is thoroughly to be recommended.

L'hérédité en ophtalmologie (Heredity in Ophthalmology). By Jules FrançoIs. 1958. Pp. 876, 623 figs, 6 col. pl. Masson, Paris. (8,000 Fr. frs.)

Yet one more major work has emanated from the study of Jules François of Ghentan excellent and most readable account of heredity as it affects ophthalmology. There is no branch of medicine in which heredity plays a more important part, no specialty has 
given this subject more attention or contributed more richly to it, and in none is a knowledge of genetic influence on disease of more practical importance in diagnosis and treatment. Particularly is this so to-day when, with the wide control of infective diseases by antibiotic drugs, a very high proportion of the conditions which now commonly lead to blindness or visual incapacity are determined by heredity. In ophthalmological literature there is no better assessment of this important branch of knowledge than in this volume by François.

The book is large and comprehensive. It starts with a clear and concise account of the general principles of genetics, the various modes of Mendelian inheritance, the difficulties involved in the study of human genetics, and the consequent necessity to rely largely on statistical methods in its interpretation. A section follows on the application of these principles to ophthalmological problems, and the remainder of the volume discusses seriatim the vast number of ocular conditions-congenital deformities, abiotrophies, phakomatoses, neoplasms, endocrine disturbances, metabolic anomalies, functional conditions, and multiple syndromes - the incidence or behaviour of which is determined to a greater or less extent by the influence of hereditary factors.

The writing is always interesting, clear, and concise, the pedigrees used as illustrations are well chosen and the bibliographies most valuable. Ophthalmology is deeply in the author's debt for this contribution to the literature.

Ophthalmology. Fourth Collection for the Medico-Surgical Encyclopædia. (Recueil périodique de l'encyclopédie médico-chirurgicale. 4e Cahier (Ophtalmologie) Recueil No. 54.) Edited by E. Velter and G. Renard. 1958. Éditions Techniques S.A., Paris.

The fourth collection of up-to-date leaflets contains articles on:

(1) Treatment of palpebral tumours, by M. A. Dollfus;

(2) Corneal surgery, by $\mathrm{C}$. Bonamour and Ph. Leopold;

(3) Treatment of dislocation of the lens, by A. Brini;

(4) Treatment of infantile glaucoma, by L. Paufique;

(5) Surgery of ptosis, by J. Legrand;

(6) Treatment of ocular wounds, by J. Charamis.

In all these contributions by specialists in their particular field the reader will find the most recent advances in technique, therapy, and the clinical aspects of the conditions under discussion. There are also several short annotations on specific items of current ophthalmological interest.

Lexicon Ophthalmologicum. Multilingual Ophthalmological Dictionary. Edited by M. E. Alvaro, M. Amsler, H. Arruga, G. B. Bietti, and S. Duke-Elder. 1959. Pp. vi + 217. Karger, Basel. (34 Swiss frs).

To review a dictionary is unusual and one cannot, perhaps, do better than quote an extract from the preface written by Sir Stewart Duke-Elder, who explains why this particular work came into being:

"The International Council of Ophthalmology has sponsored the writing of this dictionary to help the ophthalmologist to read, and perhaps to write, in a language other than his own, by providing him with the translations of the technical words commonly used in his specialty. The five languages most important in modern ophthalmological literature have been included, and Latin has been added since it so often provides a common root and may serve as a guide in the interpretation of technical terms in other less widely used tongues." 
The real worth of a dictionary appears only with constant use and the planning and technical arrangement of the Lexicon Ophthalmologicum invite the language-shy reader to consult its pages and to plunge into what is-to the reviewer at least-the fascinating study of a common term in a multilingual setting. The editors are to be complimented on the direct simplicity of their method of compilation. The dictionary should prove a most helpful adjuvant to ophthalmologists throughout the world.

\section{NOTES}

Dr. Goodwin M. Breinin, Chairman of the Department of Ophthalmology and Kirby Professor of Research Ophthalmology, New York University-Bellevue Medical Center, has been named recipient of the 1959 Edward Lorenzo Holmes Memorial Award of the Institute of Medicine of Chicago, in recognition of his important contributions in the field of ophthalmology, particularly his investigations concerning the neuromuscular control of the ocular muscles and the development of ocular electromyography in advancing the knowledge of strabismus. In addition, Dr. Breinin pioneered in the study of drugs affecting the secretory epithelium of the ciliary body and their application in the therapy of glaucoma.

\section{OBITUARY}

\section{WILLIAM CLARK SOUTER}

Dr. W. Clark Souter, the last of the older school of ophthalmologists in Aberdeen, died at Elgin on March 1, 1959, at the 'age of 79.

Educated at Aberdeen Grammar School and at Aberdeen University, he graduated M.B., Ch.B., with honours, in 1903 . He studied the excretion of purine bodies, and for this work received his M.D., with honours, in 1906. Soon after graduation, and at the request of Sir Alexander Ogston, he went as surgeon in the ship Terra Nova, which went to relieve the Scott expedition in the Antarctic in 1903-4. For this service he became one of the few to whom the Polar Medal has been awarded.

His main interest was early directed to ophthalmology. He did postgraduate work at Moorfields and gained the Diploma in Ophthalmology of Oxford University in 1919. After further clinical experience at the Royal London Ophthalmic Hospital, he was appointed to the staff of the Aberdeen Royal Infirmary, and was associated with this institution until his retirement in 1946, when he was elected honorary consultant in ophthalmology. He was also surgeon to the Aberdeen Eye Institution and ophthalmic surgeon to the Aberdeen Maternity Hospital. The medical aspect of ophthalmology formed his most absorbing interest. Among his publications were papers on uveo-parotid fever and auto-eversion of the upper lids: 